\title{
Association between weight gain, psychological, sociodemographic factors, and physical activity in bariatric patients: a complex system
}

Nélio Barreto Vieira'; Paulo Felipe Ribeiro Bandeira²; Gyllyandeson Delmondes; ${ }^{3}$ Rafaela

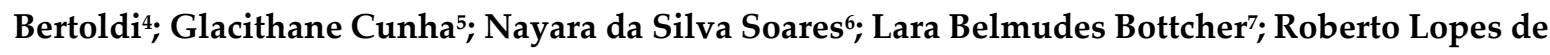
Almeidas; Maria Eveline Vieira9; Sedigheh Salamii ${ }^{10}$; Marta Kerntopf ${ }^{11}$; Clarice Martins ${ }^{12}$; Victor Zaia $^{13}$

1 Pesquisa e Inovação do Centro Universitário Saúde ABC,Faculdade de Medicina do ABC (FMABC), Universidade Federal do Cariri - UFCA. Brazil; neliobv@hotmail.com

2 Grupo de Estudo, Avaliação e Pesquisa em Avaliação Motora-GEAPAM, Departamento de Ciências Biológicas e Saúde doUniversidade Regional do Cariri - URCA; paulo.bandeira@urca.br

3 Department of Biological Chemistry; Universidade Regional do Cariri - URCA, Brazil; gyllyandesondelmondes@gmail.com

4 Universidade Federal do Rio Grande do Sul - UFRGS, Brazil; rafaela.bertoldi@ufrgs.br

5 Grupo de Estudo, Avaliação e Pesquisa em Avaliação Motora-GEAPAM, Departamento de Ciências Biológicas e Saúde doUniversidade Regional do Cariri - URCA; nayara.soares@urca.br

6 Grupo de Estudo, Avaliação e Pesquisa em Avaliação Motora-GEAPAM, Departamento de Ciências Biológicas e Saúde doUniversidade Regional do Cariri - URCA; glacithanecunha@gmail.com

7 University Center Doctor Leão Sampaio - UNILẼ̃O, Brazil; larabottcher@hotmail.com

8 Department of Morphology and Physiology, Centro Universitário Saúde ABC (FMABC), Faculdade de Medicina do $\mathrm{ABC}$, Brazil. roberto.almeida@fmabc.net

9 Faculdade de Juazeiro do Norte - FJN eveline09-menp@hotmail.com

10 Alzahra University, Tehran, Iran; sed60sal@gmail.com

${ }^{11}$ Department of Biological Chemistry; Universidade Regional do Cariri - URCA, Brazil; martaluiz@yahoo.com.br

12 Department of Physical Education; Universidade Federal a Paraíba - UFPB; Research Centre of Physical Activity, Health and Leisure, Faculty of Sports Sciences, University of Porto. claricemartinsufpb@gmail.com

${ }_{13}$ Research an Innovation of the Centro Universitário Saúde ABC, Faculdade de Medicina do ABC (FMABC). victor.zaia@fmabc.br

* Correspondence: Regional University of Cariri, Rua Cel. Antônio Luís - 116 1, 63.100-000, Crato, Ceará, Brazil. Email: paulo.bandeira@urca.br (P.F.R. Bandeira).

\begin{abstract}
Weight gain affects about $10-20 \%$ of patients after bariatric surgery. It is a phenomenon that is difficult to understand and to intervene due to its complexity and etiological heterogeneity. In the present study, we investigated, from a network analysis perspective, the associations between weight regain, psychological, sociodemographic factors and physical activity in patients undergoing bariatric surgery. The sample consisted of 124 patients, of both sexes, aged $39 \pm 9.1$ years, who had undergone surgical intervention for more than 18 months. After voluntary consent, respondents answered questionnaires and instruments directly on the Google Forms platform. The results indicated that weight gain was negatively associated with the items of depression, anxiety and stress, binge eating and with the dimensions of the personality questionnaire (negative affectivity -0.182 ; detachment -0.078 ; antagonism -0.107 ; disinterest -0.198 and psychoticism -0.158 ). The centrality indicators revealed that the characteristics of disinterest and negative affectivity and most of the items on the depression, anxiety and stress scale had a greater expected influence (values from 1,043 to 1,502), indicating that these are the most sensitive variables to intervention and who need more attention from health professionals.
\end{abstract}

Keywords: obesity; bariatric surgery; adaptive complex system; network analysis. 


\section{Introduction}

Obesity is a worldwide epidemic. In 2016, more than 1.9 billion adults were overweight and of these, more than 650 million were obese [1]. Morbid obesity is the most severe form of this disease, reducing life expectancy between 10 and 15 years [2] This pathology is defined as a metabolic disease of genetic etiology and aggravated by exposure to environmental, psychological, cultural, economic, social phenomena. Still being associated with factors such as age, race, gender, and sedentary lifestyle, proving its multifactoriality and complexity [3]. Results of epidemiological studies, clinical trials and meta-analyses often support the association between psychological aspects and obesity in all groups of populations examined [4].

Clinical treatment for obesity includes nutritional therapy, medication and physical activity. When there is failure in this treatment and obesity becomes morbid, bariatric surgery is indicated [5]. Unfortunately, in an average period of 18 months after surgery, $10-20 \%$ of operated patients gain weight $[6,7,8]$. The etiology of regain is multifactorial, making it difficult to establish its causes. Eating behavior, sedentary lifestyle, and psychological factors such as depression, anxiety, stress, binge eating, personality, body self-image, and how the individual faces external stress factors, may be listed as the several factors that influence weight gain. Indeed, patients with anxious behaviors tend to eat more after bariatric surgery, and those with greater capacity for concentration, organization and systematic control would likely avoid weight gain [9]. These characteristics may be linked to the evaluation that individuals have about eating behaviour (difference between the real and the perceived). Studies have even indicated that this failure of evaluative capacity is one of the best predictors of weight gain, once the patient does not perceive what he eats, how much he eats, what habits are healthy, including physical activity, and which are not $[10,11,12]$. Though all these factors seem to be intrinsically related in the same individual, the relationship among them is still unclear [6].

Obesity and weight gain are difficult to evaluate and intervene due to the heterogeneity and complexity of the factors involved, arising from several areas of knowledge and intervention. This multifactorial characterizes obesity and weight regain as a complex adaptive system (ACS). Adaptive complex systems present heterogeneous agents that interact nonlinearly and are sensitive to small changes. In this sense, the perspective of networks can be proposed as an excellent tool to evaluate complex systems, as in the health area [13] and specifically in obesity [14]. Thus, the aim of the present study was to evaluate possible associations between weight gain, psychological factors (anxiety, stress, depression, and personality), sociodemographic and physical activity from a network perspective in patients undergoing bariatric surgery.

\section{.2. Materials and Methods}

This is a quantitative and cross-sectional study. To improve the process of scientific transparency, the STROBE protocol [15] and CHERRIES [16] were used.

\subsection{Participants}

The sample was composed of convenience. Invitations were sent to 300 bariatric patients over 18 months old, of which only 124 voluntarily agreed to participate in the research, and it is emphasized that all patients were operated by the same surgeon. The individuals in the sample had a mean age of $39 \pm 9.1$ years, of both sexes, followed by the multidisciplinary health team of the Nucleus - Health Services located in the municipality of Juazeiro do Norte, in the Metropolitan region of Cariri, Ceará, Brazil.

\subsection{Procedures}

An online invitation to participate in this study was directed, by e-mail or social network application, individually to each participant, where they were informed about the objectives, protocols and procedures of the research. After voluntary consent to participate in this study, the interviewees answered the instruments directly on the Google Forms online platform. 


\subsection{Measures}

\subsubsection{Sociodemographic and clinical factors}

A questionnaire was used to obtain information on the clinical (history of chronic diseases and medication use) and socio-economic variables: age, gender, marital status, income and years of study.

\subsubsection{Eating Behavior}

To evaluate eating behavior, two instruments were applied: Bulimic Investigatory Test of Edinburgh (BITE) [17], in its version in Portuguese [18], and the Periodic Binge Eating Scale (ECAP) [19] also in its Brazilian version [20].

The BITE is a self-administered questionnaire, composed of two scales: one of symptoms (composed of 30 items) and one of severity (3 dimensional items), the sum of the two scores produces a total score. The symptom scale ranges from 0 to 30 points, and "yes" answers represent the presence of symptom, worth 1 point, and the "no" responses represent no symptom (0). In questions 1, 13, 21, 23 and 31, it is scored inversely. After evaluation, the scale allows three classifications: High (20 points or more): considered a high score with the presence of compulsive eating behavior and a great possibility of fulfilling diagnostic criteria for bulimia nervosa. Mean (10 to 19 points): suggests unusual dietary pattern, usually, without the presence of all criteria for bulimia classification. Low (below 10 points): behavior within normal limits [17,18].

ECAP is an appropriate instrument to distinguish individuals who are candidates for bariatric surgery according to the severity of 'periodic binge eating' (CAP) [21]. The answers are in Likert scale, composed of 62 statements grouped into 16 items. Each item contains 3 to 4 statements about behaviors and feelings related to CAP. Each selected statement is applied a score from 0 to 3 , ranging from the absence ("0") to the maximum severity ("3") of the CAP. The final score is the result of the sum of the points of each item, which allows the classification of the CAP in: absence of CAP, when the score is $\leq 17$; Moderate $\mathrm{CAP}$, score between 18 and 26; and severe CAP when the sum of the scores is $\geq 27[19,20]$.

\subsubsection{Anthropometry and Weight regain}

Height $(\mathrm{cm})$ and body mass $(\mathrm{Kg})$ were measured in the preoperative period and 1 (one) year after bariatric surgery. BMI (body mass index) was calculated by dividing body mass by square of height in meters $\left(\mathrm{Kg} / \mathrm{m}^{2}\right)$.

To evaluate weight loss and regained weight after surgery, the equation of \%TWL (Percent total weight loss) was used, considered one of the best methods to evaluate post-bariatric weight loss. Studies show that one decade after bariatric there is a physiological weight gain, which can range from $5-10 \%$ of $\%$ TWL; therefore, weight regain values higher than $15 \%$ of NADIR weight (lower body weight achieved after bariatric powders) $[22,23]$ is considered weight regain. It is expected that the nadir will be achieved in the first $12-18$ months with loss of at least $20 \%$ of the total body weight before performing the surgical procedure [22].

\subsubsection{Physical activity}

The level of physical activity (PA) was assessed using the summarized version of the International Physical Activity Questionnaire (IPAQ) validated in Brazil by Matsudo et al. [25]. The PA level is classified as vigorous, moderate or mild, according to the time spent by the interviewee in each physical activity. After evaluating the time spent in PA, the individuals are classified as: Sedentary: individuals who do not perform PA for at least 10 minutes continuously during the week. Insufficiently active: individuals who practice PA for at least 10 minutes continuously per week, but insufficiently to be classified as active. Active: individuals who meet the following recommendations: (a) vigorous PA $\geq 3$ days/week and $>20 \mathrm{~min} /$ session; (b) moderate exercise or walk $\geq 5$ days/week and 
$>30 \mathrm{~min} / \mathrm{session;}$ (c) any activity $>5$ days/week and >150 min/week. Very Active: individuals who meet the following recommendations: (a) vigorous $\mathrm{AF} \geq 5$ days / week and $>30 \mathrm{~min} / \mathrm{session}$; (b) vigorous $\mathrm{PA} \geq 3$ days/week and $>20 \mathrm{~min} / \mathrm{session}$ and/or 3 to 5 days/week walk for $\geq 30 \mathrm{~min} / \mathrm{session}$ [25.26].

\subsubsection{Anxiety, Stress and Depression}

Symptoms of stress, anxiety and depression were measured and differentiated using the Depression, Anxiety and Stress Scale - Short Form (DASS-21) instrument [27]. In this study, the DASS21 version was used for Brazilian adults translated and valid by Machado and Bandeira [28]. The answers are at a 4-point Likert scale between "0" (does not apply to me) to "3" (it applies a lot to me, or most of the time). Based on the tripartite model, dass-21 groups the symptoms of anxiety and depression into three basic structures. The first, characterized by the presence of negative affect, such as insomnia, discomfort, irritability and depressed mood, which are nonspecific symptoms that are included in both depression and anxiety. The second is defined by the presence of specific symptoms for depression: anhedonia and absence of positive affection. The latter structure refers to the specific symptoms for anxiety: hyperactivity and somatic tension. The result is obtained from the sum of the scores of the 7 items of each of the 3 subscales, being possible to obtain three distinct grades, one for each subscale, in which the minimum score is " 0 " and the maximum "21". Higher scores indicate more negative affective states [29].

\subsubsection{Personality}

Pathological personality traits were evaluated using the Personality Inventory for DSM-5 Short Form (PID-5-SF) [30]. It is a self-applicable instrument composed of 100 items extracted from the Personality Inventory for DSM-5 (PID-5) [31], which was reduced and validated by Timm et al. [30] regarding its reliability and efficiency of trait criteria of the alternative model for personality disorders in the DSM-5. Items are evaluated on a Likert scale with scores ranging from "0" (too false or often false) to "3" (true or often true). The scores of the PID-5-SF domains are calculated by adding scores from the three scales that contribute to the evaluation of the pathological personality traits of the hybrid model proposed by the DSM-5 [30,31]. In the present study we used the overall score of each dimension of PID-5.

\subsection{Statistical analysis}

Descriptive statistics (means and standard deviations) were used for continuous variables and frequency distributions (absolute and relative values) for categorical variables. A network analysis was used to evaluate the association between biological and psychosocial variables. Indicators of closenness and expected influence were reported. Variables with higher expected influence values are more sensitive to change and can act as a hub by connecting other pairs of variables on the network. A variable with a high closeness value will be quickly affected by changes anywhere in the network and can also affect other parts. The algorithm "Fruchterman - Reingold" was applied; therefore, the data were shown in the relative space in which the variables with stronger permanent statistics together and with less strongly applied variations repelled each other. To improve network accuracy, we use the "Markov random fields in pairs" model. The algorithm adds a penalty "L1" (regularized neighborhood regression). The adjustment is estimated by a less complete selection and contraction operator (Lasso) that controls the sparse network. The extended Bayesian information criterion (EBIC) was observed to select the Lambda from the regularization parameter. EBIC uses a hyperparameter $(y)$ that determines how much EBIC selects sparse models. We determined the value of y at 0.25 (range from 0 to 0.50 ), which is a more parsimonious value when we have exploratory networks, as in the present study. Network analysis uses regularized algorithms of lower absolute reduction and selection operator (LASSO) to obtain the precision matrix. This matrix, when standardized, represents the associations between the variables present in the network. For a better visualization of the weight matrix, the network is presented in a chart that includes the variables (nodes) and relationships (lines). The blue color represents positive associations, and the red color 
represents negative associations. The thickness and intensity of colors represent the magnitude of the associations. The analyses were performed through the $\mathrm{R}$ language, by RStudio, using the basic packages and the qgraph.

\subsection{Ethical aspects}

The Helsinki Declarations' ethical aspects were followed. This study was approved by the Brazil National Board of Research Ethics under the requirement of proper informed consent. All participants were volunteers and signed a consent form to participate in the research. The evaluation methods and procedures were approved by the Research Ethics Committee of Health Science Center of Universidade Regional do Cariri - URCA (protocol n. 4.067.470)

\section{Results}

Sociodemographic characteristics and reported PA levels of participants with and without weight gain are presented in Table 1 . In the weight gain group $(\mathrm{N}=42)$, most of the participants were female $(\mathrm{N}=97)$, satisfied with the current weight $(71.4 \%)$, had an income of between 4 and 10 minimum wages (59.5\%), had completed high school (57.1\%), and considered themselves physically active $(25.6 \%)$. In the variable people in the house, two categories presented the same value (28.5\%), being 1 and 3 people living in the house. In the group that did not present weight gain (N=82), most participants were also female, were satisfied with their weight (53.6\%), lived with up to 3 people in the house (39.0\%), had an income between 10 2,20 000 minimum wages (41.4\%), had completed high school (65.8\%), and considered themselves physically active (74.3\%). Only in the income variable was found a statistically significant difference between the group with and without weight gain $(x 2=13.58$; $\mathrm{p}=0.009)$.

Table 1. Sociodemographic characteristics of the participants.

\begin{tabular}{|c|c|c|c|c|}
\hline Variable & $\begin{array}{c}\mathrm{M}(\mathrm{SD}) \text { ou } \mathrm{N} \\
(\%)\end{array}$ & $\mathrm{M}(\mathrm{SD})$ ou N (\%) & t ou $x^{2}$ & $\begin{array}{c}\mathrm{p}- \\
\text { value }\end{array}$ \\
\hline & Regain (N=42) & $\begin{array}{l}\text { Without regain } \\
\qquad(\mathrm{N}=82)\end{array}$ & & \\
\hline Age (years old) & $38.04(9.2)$ & 40.13(9.9) & -1.13 & 0.26 \\
\hline \multicolumn{5}{|l|}{ Gender } \\
\hline Male & $10(23.8 \%)$ & $17(20.7 \%)$ & & \\
\hline Female & $32(76.2 \%)$ & $65(79.3 \%)$ & 0.15 & 0.69 \\
\hline \multicolumn{5}{|c|}{$\begin{array}{l}\text { Satisfaction with current } \\
\text { weight }\end{array}$} \\
\hline Dissatisfied & $12(28.5 \%)$ & $38(46.3 \%)$ & & \\
\hline Satisfied & $30(71.5 \%)$ & $44(53.7 \%)$ & 3.64 & 0.056 \\
\hline \multicolumn{5}{|l|}{ People in the house } \\
\hline 1 & $12(28.5 \%)$ & $15(18.2 \%)$ & & \\
\hline 2 & $7(16.6 \%)$ & $17(20.7 \%)$ & & \\
\hline 3 & $12(28.5 \%)$ & $32(39.0 \%)$ & 3.37 & 0.49 \\
\hline 4 & $7(16.6 \%)$ & $14(17 \%)$ & & \\
\hline 5 & $4(9.5 \%)$ & $4(4.8 \%)$ & & \\
\hline
\end{tabular}

Income 


\begin{tabular}{ccccc} 
Up to 380 USD & $3(7.1 \%)$ & $2(2.4 \%)$ & & \\
380USD to 760USD & $6(14.2 \%)$ & $19(23.1 \%)$ & & \\
760USD to 1900USD & $25(59.5 \%)$ & $25(30.4 \%)$ & 13.58 & 0.009 \\
1900USD to 3800USD & $7(16.6 \%)$ & $34(41.4 \%)$ & & \\
Over 3800USD & $1(2.3 \%)$ & $2(2.4 \%)$ & & \\
& & & & \\
chooling (in years) & & & & \\
9 & $18(42.8 \%)$ & $26(31.7 \%)$ & & \\
12 & $24(57.2 \%)$ & $51(67.0 \%)$ & 1.80 & 0.40 \\
$\geq 16$ & $0(0.0 \%)$ & $1(1.3 \%)$ & & \\
Inactive & & & & \\
Active & $16(38.1 \%)$ & $21(25.6 \%)$ & 2.06 & 0.15 \\
& $26(61.9 \%)$ & $61(74.3 \%)$ & & \\
\hline
\end{tabular}

\subsection{Network Analysis}

The main results of the network indicated that weight regain was negatively associated with all items of depression, anxiety and stress, with the items of binge eating, and with the dimensions of the personality questionnaire (negative affectivity -0.182; distancing -0.078; Antagonism -0.107; Disinhibition -0.198 and Psychoticism -0.158). The regain is also associated with having a lower income (-0.292) and having a better schooling (0.255).

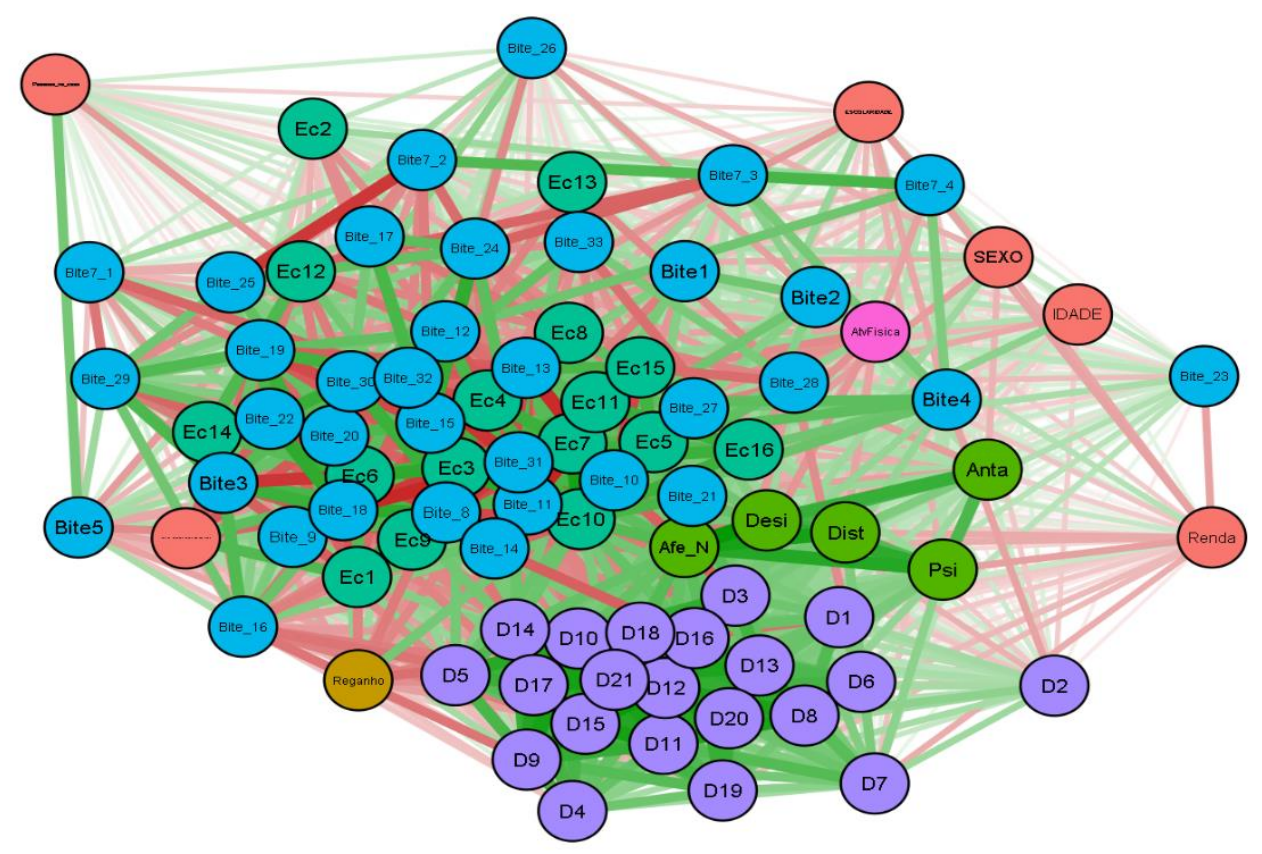

Figure 1. Associations between the variables weight gain, psychological factors (anxiety, stress, depression and personality), sociodemographic and physical activity in bariatric patients.

\subsection{Centrality measures}

Table 2 shows the network centrality measures. The personality characteristics: disinterest and negative affectivity and most items of the depression, anxiety and stress scale (D3 "I could not have positive feelings", D5 "I found it difficult to have initiative to do things", D8 "I felt i was quite nervous", D9 "I was worried about situations where I could panic and make a fool of myself", D10 "I 
felt I had no positive expectations about anything", D11 "I noticed i was getting agitated", D12 "I found it difficult to relax", D13" I felt downcast and sad", D14 " I didn't have patience with anything that interrupted what I was doing", D15 " I felt I was about to panic", D16 " I couldn't get carried away with anything", D17 " I felt i didn't have much value as a person", D18 "I felt that I was very angry", D20 "I felt scared without any reason" and D21 "I felt that life had no meaning".) had greater expected influence, ranging from 1,043 to 1,502.

The variables with the highest values of closeness were, Ec3, Ec7, Ec9, Ec10, Ec11, D14, Bite_8 "Does your eating pattern severely harm your life?", Bite_10 "Do you eat non-stop until you are forced to stop feeling physically unwell?", Bite_11"Are there times when you can only think about food?", Bite_14 "Have you ever felt an uncontrollable urge to eat and eat non-stop?", Bite_15 "When do you feel anxious), tend to eat too much?", Bite_18 "Are you ashamed of your eating habits?", Bite_31 "Your eating habits are what you might consider normal?" and Bite_32 "Do you consider yourself someone who eats compulsively?" , ranging from 1,004 to 1,968.

Table 2. Network centrality measures.

\begin{tabular}{|c|c|c|}
\hline & Closeness & Expected Influence \\
\hline GENDER & -1.730 & -0.315 \\
\hline Regain & -0.490 & -1.646 \\
\hline AGE & -1.736 & -0.424 \\
\hline Negative Affectivity & 1.389 & 1.267 \\
\hline Distancing & 0.087 & 0.878 \\
\hline Antagonism & -0.773 & 0.347 \\
\hline Disinterest & 0.790 & 1.071 \\
\hline Psychoticism & -0.303 & 0.910 \\
\hline Ec1 & 0.775 & 0.328 \\
\hline Ec2 & -1.554 & -0.481 \\
\hline Ec3 & 1.968 & 0.730 \\
\hline Ec4 & 0.964 & 0.369 \\
\hline Ec5 & 0.699 & 0.650 \\
\hline Ec6 & 0.965 & 0.119 \\
\hline Ec7 & 1.186 & 0.828 \\
\hline Ec8 & 0.340 & 0.285 \\
\hline Ec9 & 1.297 & 0.393 \\
\hline Ec10 & 1.812 & 0.990 \\
\hline Ec11 & 1.013 & 0.636 \\
\hline Ec12 & -0.515 & -0.609 \\
\hline Ec13 & -1.120 & -0.519 \\
\hline Ec14 & -0.179 & -0.008 \\
\hline Ec15 & 0.451 & 0.244 \\
\hline Ec16 & 0.282 & 0.555 \\
\hline D1 & -0.392 & 0.747 \\
\hline D2 & -1.609 & -0.098 \\
\hline D3 & 0.810 & 1.190 \\
\hline
\end{tabular}




\begin{tabular}{|c|c|c|}
\hline D4 & -0.615 & 0.497 \\
\hline D5 & 0.292 & 1.043 \\
\hline D6 & -0.479 & 0.786 \\
\hline D7 & -0.814 & 0.726 \\
\hline D8 & -0.168 & 1.301 \\
\hline D9 & -0.073 & 1.126 \\
\hline D10 & 0.833 & 1.370 \\
\hline D11 & -0.077 & 1.248 \\
\hline D12 & 0.459 & 1.357 \\
\hline D13 & 0.340 & 1.296 \\
\hline D14 & 1.117 & 1.290 \\
\hline D15 & 0.254 & 1.502 \\
\hline D16 & 0.733 & 1.374 \\
\hline D17 & 0.707 & 1.291 \\
\hline D18 & 0.635 & 1.281 \\
\hline D19 & -0.609 & 0.894 \\
\hline D20 & 0.003 & 1.383 \\
\hline D21 & 0.276 & 1.564 \\
\hline Bite1 & -0.848 & 0.251 \\
\hline Bite2 & -0.877 & 0.538 \\
\hline Bite3 & 0.246 & -0.987 \\
\hline Bite4 & -0.544 & 0.189 \\
\hline Bite5 & -1.316 & -1.025 \\
\hline Bite7_1 & -1.256 & -0.412 \\
\hline Bite7_2 & -1.136 & -0.572 \\
\hline Bite7_3 & -1.228 & -0.352 \\
\hline Bite7_4 & -1.156 & -0.208 \\
\hline Bite_8 & 1.269 & -1.672 \\
\hline Bite_9 & 0.527 & -1.071 \\
\hline Bite_10 & 1.004 & -1.743 \\
\hline Bite_11 & 1.376 & -1.762 \\
\hline Bite_12 & 0.511 & -1.159 \\
\hline Bite_13 & 0.853 & 0.387 \\
\hline Bite_14 & 1.224 & -1.706 \\
\hline Bite_15 & 1.069 & -1.488 \\
\hline Bite_16 & -0.192 & -1.337 \\
\hline Bite_17 & -0.818 & -0.770 \\
\hline Bite_18 & 1.211 & -1.581 \\
\hline Bite_19 & 0.444 & -0.857 \\
\hline Bite_20 & 0.638 & -1.229 \\
\hline Bite_21 & 0.733 & 0.749 \\
\hline Bite_22 & 0.490 & -1.248 \\
\hline Bite_23 & -1.940 & -0.060 \\
\hline Bite_24 & -0.304 & -0.975 \\
\hline
\end{tabular}




\begin{tabular}{ccc} 
Bite_25 & -0.652 & -0.777 \\
Bite_26 & -1.759 & -0.356 \\
Bite_27 & 0.465 & 0.386 \\
Bite_28 & -0.443 & -1.314 \\
Bite_29 & -0.399 & -0.470 \\
Bite_30 & 0.603 & -1.230 \\
Bite_31 & $\mathbf{1 . 7 3 1}$ & 0.683 \\
Bite_32 & $\mathbf{1 . 0 4 1}$ & -1.605 \\
Bite_33 & -0.656 & -1.035 \\
Renda & -1.881 & -1.261 \\
People in the house & -2.372 & -0.389 \\
Schooling & -1.660 & -0.930 \\
Current Weight Satisfaction & -0.362 & 0.073 \\
Physical Activity Level & -0.876 & -1.440 \\
\hline
\end{tabular}

\section{Discussion}

The aim of this study was to evaluate the possible associations between personality, psychological, sociodemographic factors, physical activity, eating behavior and the influences of these variables on weight regain of patients undergoing bariatric surgery, considering the interactions between these variables in an adaptive complex system measured in a network analysis, characterizing a novelty in the literature.

Our findings revealed that there is a negative relationship between weight gain and personality traits: disinterest and negative affectivity (PID-5-SF) and these are associated with depressive, anxiety and stress behaviors (DASS 21) reflecting on bulimic and/or compulsive eating behavior (BITE and ECAP). The literature is scarce in the investigation between changes in eating behavior and weight recovery after bariatric surgery $[32,33]$. However, some studies have observed that the mental health of the patient is one of the most important factors in the maintenance and weight gain after surgical intervention $[34,35,36]$. In this sense, the occurrence of binge eating in obese candidates for bariatric surgery is frequent $[37,38,39]$. In the study by Cella et al. [39], the authors observed that the prevalence of periodic compulsive eating disorders in candidates for bariatric surgery ranges from 2 to $49 \%$ [40].

Similar studies, although with different statistical perspectives, demonstrate that risk factors that compromise physical and psychological well-being, both in the preoperative period and in the postoperative period of bariatric surgery, are associated with unbalanced diet, lack of physical activity and psychological disorders [41]. Among mental diseases, those that manifest symptoms of depressive behaviors are the most prevalent in obese patients who are candidates for bariatric surgery, and in bariatric patients. These factors, consequently, lead to an increased risk of weight gain after surgery, due to the associations of these mental disorders with compulsive eating behaviors $[34,42,43]$.

Although the impact of psychological programs before and after bariatric surgery is known, there is still a need in the literature of studies that objective to investigate the complex interactions between the various factors involved in obesity and weight gain after bariatric surgery, so that more effective therapeutic programs can be established. A recent study, with network analysis, identifies the importance of personality traits and anxiety symptoms in bariatric patients. However, it has as limitations the short follow-up period of individuals (09 months) and does not include depressive symptoms in their analysis [44]. In our study beyond personality, we added information about 
anxiety, depression and stress and how these factors act in a network with sociodemographic factors, binge eating, physical activity and weight gain.

The factors that predict the susceptibility of patients to weight gain after bariatric surgery are not fully known [33]. Studies state that weight recovery is a multifactorial process of complex etiology $[45,46]$. In our study we also investigated through an analysis of weight gain networks, which are the most sensitive factors to interventions from network indicators. We found that the items referring to personality characteristics: disinterest and negative affectivity and most items of the depression, anxiety and stress scale presented high expected influence, these items need to be urgently treated in these patients by professionals from different areas. We also elucidate from the indications of closenness centrality that the items of binge eating will be the most benefited from multidisciplinary interventions, which indicates that the treatment of patients with weight gain in the present study should focus on these psychological aspects, which, consequently, would improve the compulsive eating behavior. Weight gain is a complex problem that is difficult to understand and intervene, so in our study we suggest that this phenomenon should be treated as a complex system. The centrality indicators also allow us to evaluate which are the variables that are most sensitive to the intervention and those that will more quickly receive the effect of the intervention, this perspective can be useful to optimize intervention studies in the health area.

\section{Conclusion}

The current results indicated that binge eating items could be the most benefited from inventions in psychological aspects to avoid weight gain in the postoperative period of bariatric patients. The present study provides a new approach to evaluate interactions between weight gain and its correlates, as a complex adaptive system. Although complex systems are difficult to intervene, this study highlights important subside to plan complex interventions in complex systems, based on the centrality indicators.

\section{Author Contributions:}

Conflicts of Interest: The authors declare no conflict of interest.

\section{References}

1. World Health Organization - WHO. Obesity and overweight. 2020. Available online: https://www.who.int/news-room/fact-sheets/detail/obesity-and-overweight (accessed on 21 September 2020)

2. Fontaine, K. R.; Redden, D.T.; Wang, C.; Westfall, A.O.; Allison, D.B. Years of life lost due to obesity. JAMA 2003, 289, 187-193.

3. Hammond, R.A. Complex systems modeling for obesity research. Prev Chronic Dis. 2009, 6, A97.

4. Jantaratnotai, N.; Mosikanon, K.; Lee, Y.; McIntyre, R.S. The interface of depression and obesity. Obes Res Clin Pract. 2017, 11, 1-10.

5. Baltieri, L.; Santos, L.A.D.; Rasera-Junior, I.; Montebelo, M.I.D.L.; Pazzianotto-Forti, E.M. Use of positive pressure in preoperative and intraoperative of bariatric surgery and its effect on the time of extubation. Rev Bras Anestesiol 2015, 65, 130-135.

6. Freire, R.H.; Borges, M.C.; Alvarez-Leite, J.I.; Correia, M.I.T.D. Food quality, physical activity and nutritional follow-up as determinant of weight regain after Roux-en-Y gastric Bypass. Nutrition 2012, $28,53-8$. 
7. Magro, D.O.; Geloneze, B.; Delfini, R.; Pareja, B.C.; Callejas, F.; Pareja, J.C. Long-term weight regain after gastric bypass: a 5-year prospective study. Obes Surg 2008, 18, 648-51.

8. Sjöström, L.; Narbro, K.; Sjöström, C.D.; Karason, K.; Larsson, B.; Wedel, H.; Lystig, T.; Sullivan, M.; Bouchard, C.; Carlsson, B.; Bengtsson, C.; Dahlgren, S.; Gummesson, A.; Jacobson, P.; Karlsson, J.; Lindroos, A.K.; Lönroth, H.; Näslund, I.; Olbers, T.; Stenlöf, K.; Torgerson, J.; Agren, G.; Carlsson, L.M. Effects of bariatric 244 surgery on mortality in Swedish obese patients. N Engl J Med 2017, 357, 741-752.

9. Gade, H.; Friborg, O.; Rosenvinge, J.; Småstuen, M.; Hjelmesæth, J. The Impact of a Preoperative Cognitive Behavioural Therapy (CBT) on Dysfunctional Eating Behaviours, Affective Symptoms and Body Weight 1 Year after Bariatric Surgery: A Randomised Controlled Trial. Obes Surg 2015, 25, $2112-$ 2119 .

10. Byrne, S.M.; Cooper, Z.; Fairburn, C.G. Psychological predictors of weight regain in obesity. Behav Res Ther 2004, 42, 1341-1356.

11. da-Luz, F.Q.; Swinbourne, J.; Sainsbury, A.; Touyz, S.; Palavras, M.; Claudino, A.; Hay, P. Hapifed: A healthy approach to weight management and food in eating disorders: A case series and manual development. J Eat Disord 2017, 5, 1-11.

12. Bottcher, L.B.; Bandeira, P.F.R.; Vieira, N.B.; Zaia, V.; Lopes, D.A.R. Quality of Life, BMI, and Physical Activity in Bariatric Surgery Patients: a Structural Equation Model. Obes Surg 2020, 30, 29272934.

13. Caldarelli, G.A. Perspective on Complexity and Networks Science. J. Phys. Complex. 2020, 1, 1-5.

14. Hammond, R.A. Peer reviewed: complex systems modeling for obesity research. Prev Chronic Dis 2009, 6 .

15. Strengthening the reporting of observational studies in epidemiology - STROBE STATEMENT. STROBE checklists. 2007. Available online: https://www.strobestatement.org/fileadmin/Strobe/uploads/checklists/STROBE checklist v4 cross-sectional.pdf (accessed on 1 December 2020)

16. Eysenbach, G. Improving the Quality of Web Surveys: The Checklist for Reporting Results of Internet E-Surveys (CHERRIES). J Med Internet Res 2004, 6, 1-6.

17. Hendrson, M.; Freeman, C.P.L. A self-rating scale for bulimia - the BITE. Br J Psychiatry 1987, 50, $18-24$.

18. Cordás, T.A.; Hpchgraf, P.B. O "BITE": instrumento para avaliação da bulimia nervosa versão para o português. J Bras Psiquiatr 1993, 42, 141-144.

19. Gormally, J.; Black, S.; Daston, S.; Rardin, D. The assessment of binge eating severity among obese persons. Addict Behav 1982, 7, 47- 55.

20. Freitas, S.; Lopes, C.S.; Coutinho, W.; Appolinário, J.C. Tradução e adaptação para o português da Escala de Compulsão Alimentar Periódica. J Bras Psiquiatr 2001, 23, 215-220.

21. Grupski, A.E.; Hood, M.M.; Hall, B.J.; Azarbad, L.; Fitzpatrick, S.L.; Corsica, J.A. Examining the Binge Eating Scale in screening for binge eating disorder in bariatric surgery candidates. Obes Surg 2013, 23, 1-6.

22. Voorwinde, V.; Steenhuis, I.H.M.; Janssen, I.M.C.; Monpelier, V.M.; van Stralen, M.M. Definitions of Long-Term Weight Regain and Their Associations with Clinical Outcomes. Obes Surg 2020, 30, $527-536$.

23. Sjöström L. Review of the key results from the Swedish Obese Subjects (SOS) trial - a prospective controlled intervention study of bariatric surgery. J Intern Med. 2013, 273, 219-34. 
24. Corcelles, R.; Boules, M.; Froylich, D.; Hag, A.; Daigle, C.R.; Aminian, A.; Brethauer, S. A.; Burguera, B.; Schauer, P.R. Total Weight Loss as the Outcome Measure of Choice After Roux-en-Y Gastric Bypass. Obes Surg 2016, 26, 1794-8.

25. Matsudo, S.; Araújo, T.; Matsudo, V.; Andrade, D.; Andrade, E.; Oliveira, L.C.; Braggion, G.. Questinário internacional de atividade física (IPAQ): estudo de validade e reprodutibilidade no Brasil. Rev Bras Ativ Fís Saúde 2001, 2, 5-18.

26. Marshall, A.; Bauman, A. The international physical activity questionnaire: summary report of the reliability\& validity studies. IPAQ Executive Committee 2001, 1-25.

27. Lovibond, P.F.; Lovibond, S.H. The structure of negative emotional states: Comparison of the Depression Anxiety Stress Scales (DASS) with the Beck depression and anxiety inventories. Behav Res Ther 1995, 33, 335-343.

28. Machado, W. L., \& Bandeira, D. R. (2013). Adaptação e validação da Depression, Anxiety and Stress Scale (DASS-21) para o Português brasileiro. Manuscript submitted for publication. [ Links ]

29. Watson, D.; Weber, K.; Assenheimer, J.; Clark, L.; Strauss, M.; McCormick, R. Testing a tripartite model: I. Evaluating the convergent and discriminant validity of Anxiety and Depression Symptom Scales. J. Abnorm. Psychol 1995, 104, 3-14.

30. Thimm, J.C.; Jordan, S.; Bach, B. The Personality Inventory for DSM-5 Short Form (PID-5-SF): psychometric properties and association with big five traits and pathological beliefs in a Norwegian population. BMC Psychol 2016, 4, 1-11.

31. American Psychiatric Association - APA. The Personality Inventory for DSM-5 (PID5)-Adult. 2013b. Available online: https://www.psychiatry.org/File Library/Psychiatrists/Practice/DSM/APA DSM5 The-Personality-Inventory-For-DSM-5-Full-

Version-Adult.pdf (accessed on 2 April 2020).

32. Devlin, M.J.; King, W.C.; Kalarchian, M.A.; Hinerman, A.; Marcus, M.D.; Yanovski, S.Z.; Mitchell, J.E. Eating pathology and associations with long-term changes in weight and quality of life in the longitudinal assessment of bariatric surgery study. Int J Eat Disord 2018, 51, 1322-1330.

33. Freire, C.C.; Zanella, M.T.; Segal, A.; Arasaki, C.H.; Matos, M.I.R.; Carneiro, G. Associations between binge eating, depressive symptoms and anxiety and weight regain after Roux-en-Y gastric bypass surgery. Eat Weight Disord 2020.

34. Pinto-Bastos, A.; de Lourdes, M.; Brandão, I.; Machado, P.P.; Conceição, E.M. Weight loss trajectories and psychobehavioral predictors of outcome of primary and reoperative bariatric surgery: a 2-year longitudinal study. Surg Obes Relat Dis 2019, 15, 1104-1112.

35. Odom, J.; Zalesin, K.C.; Washington, T.L.; Miller, W.W.; Hakmeh, B.; Zaremba, D.L.; Chengelis, D.L. Behavioral predictors of weight regain after bariatric surgery. Obes Surg 2010, 20, 349-356.

36. Scholtz, S.; Bidlake, L.; Morgan, J.; Fiennes, A.; El-Etar, A.; Lacey, J.H.; McCluskey, S. Long-term outcomes following laparoscopic adjustable gastric banding: postoperative psychological sequelae predict outcome at 5-year follow-up. Obes Surg 2007, 17, 1220-1225.

37. Dawes, A.J.; Maggard-Gibbons, M.; Maher, A.R.; Booth, M.J.; Miake-Lye, I.; Beroes, J.M.; Shekelle, P.G. Mental Health Conditions Among Patients Seeking and Undergoing Bariatric Surgery. JAMA 2016, 315, 150-163.

38. Novelle, J.M.; Alvarenga, M.S. Cirurgia bariátrica e transtornos alimentares: Uma revisão integrativa. Braz. J. Psychiatry 2016, 65, 262-285.

39. Cella, S.; Fei, L.; D'amico, R.; Giardiello, C.; Allaria, A.; Cotrufo, P. Binge eating disorder and related features in bariatric surgery candidates. Open Medicine 2019, 14, 407-415.

40. Meany, G.; Conceição, E.; Mitchell, J.E. Binge eating, binge eating disorder and loss of control eating: effects on weight outcomes after bariatric surgery. Eur Eat Disord Rev 2014, 22, 87-91.

41. Cheroutre, C.; Guerrien, A.; Rousseau, A. Contributing of Cognitive-Behavioral Therapy in the Context of Bariatric Surgery: a Review of the Literature. Obes Surg 2020, 30, 3154-3166. 
42. Müller, M.; Nett, P. C.; Borbély, Y.M.; Buri, C.; Stirnimann, G.; Laederach, K.; Kröll, D. Mental Illness Has a Negative Impact on Weight Loss in Bariatric Patients: a 4-Year Follow-up. J Gastrointest Surg 2019, 23, 232-238.

43. Figueiredo, M.D.; Nasser, S.N.; Franco, C.B.; dos Santos, C.B.; Boguszewski, C.L.; Suplicy, H.L.; Rodrigues, A.M.; Radominski, R.B. Personality type, eating behaviour and suicide risk in women in treatment for obesity. Eat Weight Disord 2020.

44. Monteleone, A.M.; Cascino, G.; Solmi, M.; Pirozzi, R.; Tolone, S.; Terracciano, G.; Parisi, S.; Cimino, M.; Monteleone, P.; Maj, M.; Docimo, L. A network analysis of psychological, personality and eating characteristics of people seeking bariatric surgery: Identification of key variables and their prognostic value. J Psychosom Res 2019, 120, 81-89.

45. Monpellier, V.M.; Janssen, I.M.; Antoniou, E.E.; Jansen, A.T. Weight change after Roux-en Y gastric bypass, physical activity and eating style: is there a relationship? Obes Surg 2019, 29, 526-533. 46. Sarwer, D.B.; Allison, K.C.; Wadden, T.A.; Ashare, R.; Spitzer, J.C.; McCuen-Wurst, C.; Wu, J. Psychopathology, disordered eating, and impulsivity as predictors of outcomes of bariatric surgery. Surg Obes Relat Dis 2019, 15, 650-655.

47. Martins, C.M.d.L.; Bandeira, P.F.R.; Lemos, N.B.A.G.; Bezerra, T.A.; Clark, C.C.T.; Mota, J.; Duncan, M.J. A Network Perspective on the Relationship between Screen Time, Executive Function, and Fundamental Motor Skills among Preschoolers. Int. J. Environ. Res. Public Health 2020, 17, 8861. 48. Bandeira, P.F.R.; Duncan, M.; Pessoa, M.L.; Soares, I.; da Silva, L.; Mota, J.; Martins, C. TGMD-2 Short Version: Evidence of Validity and Associations With Sex, Age, and BMI in Preschool Children. JMLD 2020, 8, 528-543. 